\title{
Emerging role of neuronal exosomes in the central nervous system
}

\author{
Mathilde Chivet ${ }^{1,2}$, Fiona Hemming ${ }^{1,2}$, Karin Pernet-Gallay ${ }^{2,3}$, Sandrine Fraboulet ${ }^{1,2}$ and Rémy Sadoul ${ }^{1,2 *}$ \\ ' U836, Equipe 2, Neurodégénérescence et Plasticité, INSERM, Grenoble, France \\ ${ }^{2}$ Grenoble Institut des Neurosciences, Université Joseph Fourier, Grenoble, France \\ ${ }^{3}$ U836, Plateforme de microscopie, INSERM, Grenoble, France
}

\section{Edited by:}

Claudia Verderio, CNR Institute of

Neuroscience, Italy

\section{Reviewed by:}

Eva-Maria Krämer-Albers, Johannes

Gutenberg University Mainz,

Germany

Frank Kirchhoff, University of

Saarland, Germany

*Correspondence:

Rémy Sadoul, Grenoble Institute of Neuroscience, Chemin Fortuné Ferrini, BP 170, F-38042 Grenoble,

France.

e-mail: remy.sadoul@ujf-grenoble.fr
Exosomes are small extracellular vesicles, which stem from endosomes fusing with the plasma membrane, and can be recaptured by receiving cells. They contain lipids, proteins, and RNAs able to modify the physiology of receiving cells. Functioning of the brain relies on intercellular communication between neural cells. These communications can modulate the strength of responses at sparse groups of specific synapses, to modulate circuits underlying associations and memory. Expression of new genes must then follow to stabilize the long-term modifications of the synaptic response. Local changes of the physiology of synapses from one neuron driven by another, have so far been explained by classical signal transduction to modulate transcription, translation, and posttranslational modifications. In vitro evidence now demonstrates that exosomes are released by neurons in a way depending on synaptic activity; these exosomes can be retaken by other neurons suggesting a novel way for inter-neuronal communication. The efficacy of inter-neuronal transfer of biochemical information allowed by exosomes would be far superior to that of direct cell-to-cell contacts or secreted soluble factors. Indeed, lipids, proteins, and RNAs contained in exosomes secreted by emitting neurons could directly modify signal transduction and protein expression in receiving cells. Exosomes could thus represent an ideal mechanism for inter-neuronal transfer of information allowing anterograde and retrograde signaling across synapses necessary for plasticity. They might also allow spreading across the nervous system of pathological proteins like PrPsc, APP fragments, phosphorylated Tau, or Alpha-synuclein.

Keywords: microvesicles, exosomes, inter-neuronal communication, synaptic plasticity, neurodegeneration, CNS neurons

\section{INTRODUCTION}

The development and function of mammals, like that of any multicellular organism, depends on intercellular communication. Classically, this occurs either through direct cell-to-cell interaction bringing together cell surface proteins or, at a distance, through secreted soluble molecules binding to cell surface receptors. These interactions lead to transduction of intracellular signals from the cell surface to the nucleus, where regulation of gene expression might occur. A breach of this dogma, which is based on the impermeable property of biological membranes, came from the demonstration that lipid vesicles containing RNAs and proteins released by mammalian cells, can modify the biological activity of non-contacting cells (Simons and Raposo, 2009). Microvesicles can be shed directly by budding from the plasma membrane. They can also form through budding into the lumen of endosomes and be released after fusion of the limiting membrane of endosomes to the plasma membrane. Once secreted in extracellular milieu the endosomal intraluminal vesicles (ILVs) are referred to as exosomes. Our review will stick to this strict definition of exosomes to discuss the most recent findings indicating the potential role of neuronal exosomes in intercellular communication within the normal and pathological central nervous system.

\section{WHY NEURONS COULD MAKE GOOD USE OF EXOSOMES}

It is now widely accepted that exosomes represent a way of intercellular exchange of effector molecules, which allows emitting cells to modify gene and protein expression in receiving cells. They allow transfer of membrane and cytoplasmic proteins (Thery et al., 2002; Morelli et al., 2004), as well as lipids involved in signal transduction (Laulagnier et al., 2004; Subra et al., 2010) or RNAs. Exosomal mRNAs can be translated (Valadi et al., 2007), and small RNAs, including microRNAs (miRNAs) mediate gene silencing in receiving cells (Kosaka et al., 2010; Pegtel et al., 2010; Montecalvo et al., 2012).

Functioning of the brain relies on the capacity of neurons to locally modulate each other at the level of synapses. Chemical synapses are made of a presynaptic part filled with neurotransmitter (NT) - containing vesicles and a post-synaptic part in which NT receptors are anchored at the level of the post-synaptic density (PSD). Specific patterns of stimulation of the presynaptic cell can durably increase or decrease the strength of synaptic responses, thereby reinforcing circuits underlying associations and memory. Changes in synaptic efficacy are based on modifications of the number of post-synaptic NT-receptors or of the amount of NT released pre-synaptically for a given stimulus. Changes of one 
neuron driven by another, have so far been explained by ways of classical signal transduction: NTs, lipids, or proteins secreted from one side of the synapse bind to receptors of the opposite surface. Pre-synaptic-activity substances can also be released by cell bodies and dendrites (Regehr et al., 2009). This leads to modulations of second messengers and enzymatic activities acting on effectors of the synaptic changes (adhesion molecules, neurotransmitter receptors, cytoskeleton anchors. .; Malenka and Bear, 2004). Signal transduction also leads to changes in gene expression and translation, which are needed for long-lasting synaptic modifications (Bullmore and Sporns, 2009). The efficacy of such mechanisms must deal with the extreme compartmentalization of the parenchyma. Indeed, control of transcription occurs in the nucleus far away from synapses undergoing plastic changes. Transcripts can be specifically transported along dendrites to synapses undergoing specific patterns of activation, where they are translated into proteins modifying synaptic strength. Translation of targets mediating dendritic growth can also be regulated by miRNAs, which are expressed within dendrites (Schratt et al., 2006; Siegel et al., 2009). We have recently observed that exosomes secreted by neurons contain miRNAs (unpublished observations). Given that single miRNAs have multiple targets, the impact of exosomemediated local transfer of miRNA on the pattern of translated mRNAs in receiving neurons may be quite extensive. Confined exchange of RNAs at synapses would thus certainly represent an efficient mechanism for long-term modifications of specific synapses. Therefore, the exosomal pathway may constitute a well designed mechanism for local and systemic inter-neuronal transfer of information within functional brain networks, with a complexity superior to that of direct cell-to-cell contacts or secreted soluble factors (Belting and Wittrup, 2008). The dark side would be that exosome transfer might also represent a privileged way for propagating pathological alterations throughout the brain (Fevrier et al., 2005; Aguzzi and Rajendran, 2009).

\section{ENDOSOMES IN NEURONS CONTROL SYNAPTIC PLASTICITY}

Endosomes are intracellular compartments collecting plasma membrane proteins, which are constantly renewed by constitutive or selective endocytosis (Figure 1). The first compartments to accept incoming proteins after their endocytosis are early endosomes. From there, the majority of the proteins are recycled back to the membrane. Other proteins, classically those meant for degradation, are selectively entrapped in vesicles budding from the endosomal membrane into the lumen of endosomes. Maturation of endosomes leads to individualization of multivesicular bodies (MVBs), which are large vacuoles delimited by a single membrane and containing a varying number of 50-80 nm membrane vesicles (Figure 2; Gruenberg and Stenmark, 2004; van der Goot and Gruenberg, 2006). Invagination of the endosomal membrane leading to the formation of MVBs also allows selective microautophagy of cytoplasmic proteins (Sahu et al., 2011). Membrane and cytoplasmic proteins entrapped in vesicles will be hydrolyzed after fusion of MVBs with lysosomes. They can also be expelled from cells after fusion of MVBs with the plasma membrane leading to the release of exosomes into the extracellular milieu (Figure 1; Simons and Raposo, 2009).

In neurons, endosomes are present in both pre- and postsynaptic compartments. Electron microscopy (EM) observations of the adult hippocampus revealed the presence of MVBs and sorting endosomes in dendritic shafts and inside a limited number

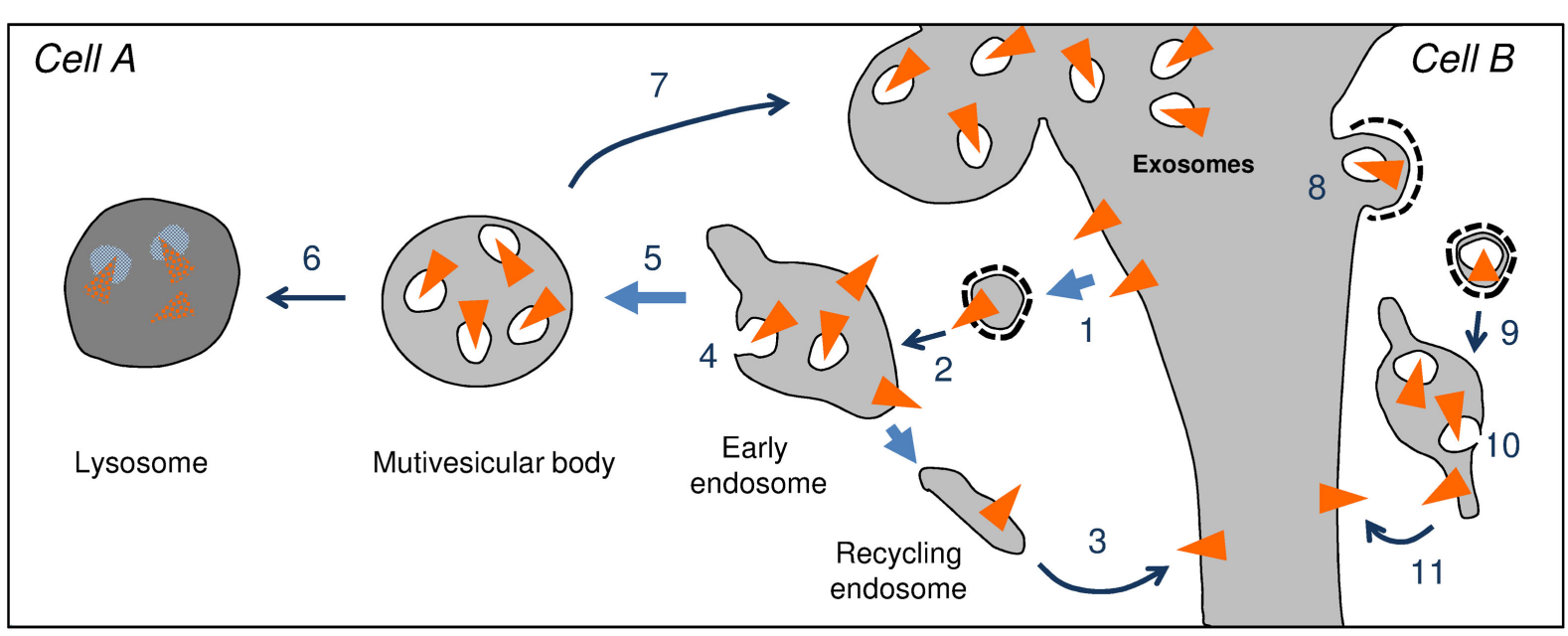

FIGURE 1 | Endosomal trafficking of transmembrane proteins (triangle). After endocytosis (1) the endocytic vesicle fuses to early endosomes (2). Proteins can be concentrated into recycling endosomes, which fuse to the plasma membrane and allow re-expression at the cell surface (3). Alternatively proteins can be entrapped in vesicles budding from the limiting membrane of the endosome (4). Maturation of the endosome leads to the individualization of a multivesicular body containing intraluminal vesicles (ILV) (5). The multivesicular body can fuse with lysosomes in which the ILVs and their cargoes are hydrolyzed (6). The multivesicular body can also fuse with the plasma membrane (7) thereby releasing ILVs. Once in the extracellular milieu ILVs are referred to as exosomes. Exosomes released by cell A, can bind to and be endocytosed by a receiving cell [cell $B, 8]$. The endocytic vesicle containing the exosome fuses with the early endosomes (9). Once inside the endosome, the exosome undergoes back-fusion with the endosomal membrane (10). Fusion of recycling endosomes to the plasma membrane allows expression of protein of the cell A at the surface of cell B. Back-fusion also allows the release of the intraluminal content of exosomes [proteins and RNAs of cell A] into the cytosol of cell B. It is important to note that steps 9,10 , and 11 remain speculative. 


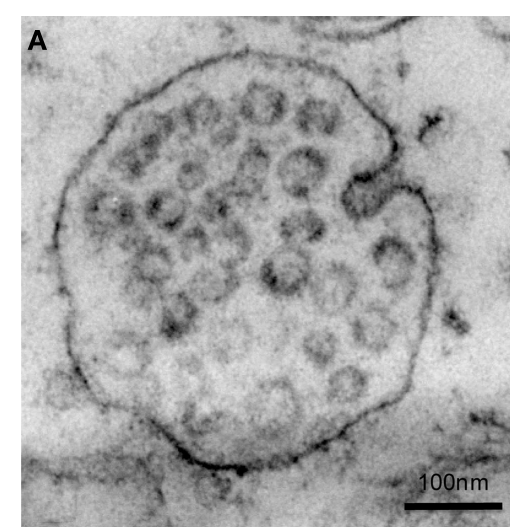

FIGURE 2 | (A) Electron micrograph of a multivesicular body present in a neuron of the $\mathrm{CA} 1$ region of the adult rat hippocampus. Note the budding of a vesicle from the limiting membrane of the MVB (upper right; Fiona Hemming, unpublished). (B) Electron micrograph of a multivesicular body in a dendrite (colored; CA1 region of an adult rat hippocampus). The protrusion of the

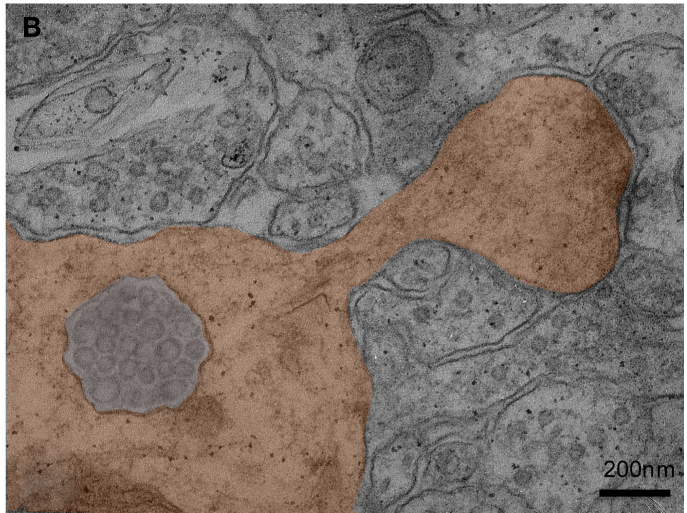

dendrite, called dendritic spine, corresponds to the post-synaptic part of a glutamatergic synapse. Two post-synaptic densities, which anchor ionotropic glutamate receptors, are visible. In this case the multivesicular body is present within the dendritic shaft at the base of the spine neck (Fiona Hemming, unpublished) of spines, which represent post-synaptic parts of glutamatergic synapses (Figure 2B; Cooney et al., 2002). Noteworthy, is that MVBs are about 50 times more represented in somatodendritic compartments than in axons (Von Bartheld and Altick, 2011). Endosome-containing spines are mostly mushroom-like spines i.e., with the most active synapses (Kasai et al., 2003). Enhancement of synaptic activity after injection of peptides known to improve cognitive functions or during kindling, significantly increased the proportion of MVBs inside spines in the dentate gyrus (Popov et al., 2008; Kraev et al., 2009). Similarly, water maze training of rats led to the migration of MVBs to the vicinity of PSDs in dendrites of CA3 pyramidal cells, while chronic restraint stress diminished the number of MVBs associated with PSDs (Stewart et al., 2005). Similarly neutrotrophic factors (BDNF, GDNF) induced a relocalization of dendritic MVBs very near PSDs of hypoglossal motoneurons (Rind et al., 2005). Thus, in the CNS, movements of MVBs to synapses are tightly linked to synaptic plasticity (Von Bartheld and Altick, 2011).

Studies of the trafficking of synaptic AMPA type-receptors, which represent the major mediators of fast synaptic transmission among glutamate receptors of the CNS, led to the demonstration that dendritic endosomes act as stores and sorting platforms for synaptic receptors (Kennedy and Ehlers, 2006). During longterm potentiation (LTP), a form of synaptic plasticity now widely accepted as a model of learning and memory processes (Ehlers, 2000), membrane insertion of new post-synaptic AMPA receptors increases excitatory post-synaptic currents thereby potentiating the synapses. Live cell imaging of dissociated hippocampal neurons demonstrated that glycine stimulation, a protocol used to induce chemical LTP through activation of synaptic NMDAreceptors, leads to the recruitment of endosomes into, or near spines and their fusion with the plasma membrane (Correia et al., 2008; Wang et al., 2008). Thereby, AMPA-Rs present in the limiting membrane of endosomes become inserted at the neuronal surface and diffuse laterally to synaptic sites where they accumulate through interaction with proteins of PSDs. Live imaging of the insertion at the plasma membrane of transferrin receptors (TfR) contained in endosomes, showed the requirement of Rab11 or syntaxin 13 for the endosomal fusion at the dendritic surface (Park et al., 2006). Accordingly, expression of a dominant negative form of Rab11 was found to inhibit LTP in slice cultures (Brown et al., 2007; Wang et al., 2008), demonstrating that endosomal fusion to the dendritic membrane is a necessary step for synaptic potentiation.

The compartments fusing at the plasma membrane of cultured neurons were identified as recycling endosomes because TfR is usually detected in recycling endosomes, and Rab11 or syntaxin 13 are known regulators of recycling endosomes. However, the strict separation between recycling endosomes and MVBs, considered as late endosomes, needs to be made with caution. Indeed, in reticulocytes, TfR is present in exosomes (Geminard et al., 2004) and Colombo and collaborators found that Rab11 is required for MVB fusion to the plasma membrane in an erythroleukemic cell line (Savina et al., 2005). Furthermore, NEEP21, known to regulate recycling of AMPA receptors at the synapse, has been localized by immunofluorescence inside TfR-containing endosomes of cultured hippocampal neurons (Steiner et al., 2005). However, EM observations of rat brain sections demonstrated that the protein is expressed at PSDs as well as in intralumenal, but not limiting, membranes of MVBs (Utvik et al., 2009). Thus, even if fluorescence data suggest that endosomes fusing to the plasma membrane during synaptic plasticity are recycling endosomes, one cannot yet exclude that some of these endosomes are MVBs. The final proof that MVBs fuse to the dendritic surface awaited the visualization of this process by EM and the demonstration that exosome release is modified by synaptic glutamate receptor activity.

\section{REGULATED SECRETION OF EXOSOMES BY NEURONS}

We made the first demonstration that cortical neurons in culture release exosomes (Faure et al., 2006). As in the case of other cells, exosomes isolated from neuron culture media floated on sucrose gradients at a density of $1.1-1.2 \mathrm{~g} / \mathrm{ml}$ and contained 
both Tsg101 and Alix. Tsg101 belongs to the endosomal sorting complex required for transport (ESCRT-0 to III), necessary for the making of ILVs accumulating inside MVBs (Babst, 2011). Alix is acytoplasmic protein binding to Tsg101 of ESCRT-I and CHMP4B of ESCRT-III (Missotten et al., 1999; Matsuo et al., 2004). Endophilin A, which also interacts with Alix (ChatellardCausse et al., 2002), was not detected in exosomes, demonstrating that entry of cargoes into ILVs is regulated. Other cytoplasmic proteins and enzymes were present inside exosomes, including GADPH, ubiquitin, and Hsc70. This is in good agreement with the recent finding thatHsc70 binding to GADPH drives its ESCRTdependent engulfment into MVB-ILVs (Sahu et al., 2011). Exosomes also contained AMPA-, but not NMDA-receptors and the cell adhesion molecule L1/NgCAM, which, in the central nervous system is expressed only by neurons (Maness and Schachner, 2007), thus demonstrating that exosomes are secreted by neurons. We also observed that electrical activity regulates exosomal secretion since long-term depolarization of neurons with $25 \mathrm{mM}$ potassium strongly increased the release of AMPA-R containing exosomes.

Three other studies reported secretion of exosomes by neurons (Vingtdeux et al., 2007; Putz et al., 2008; Ghidoni et al., 2009). These studies, as well as our initial one, used embryonic neurons cultured for only 3-8 days. In short term cultures, neurons make only few synapses and neurite outgrowth is still on-going. Thus, exosome release could simply reflect the fusion of late endosomes/lysosomes at growth cones necessary for neurite elongation (Arantes and Andrews, 2006).

More recently, we have studied exosome release from fully differentiated cultures (15 DIV; Lachenal et al., 2010). Dissociated cortical cells contain both glutamatergic and GABAergic neurons, which make functional networks within the second week in culture. Thus, incubation with GABA receptor antagonists, such as picrotoxin or bicuculline, alleviates inhibitory activities within the networks and increases synaptic glutamatergic activity. Picrotoxin or bicucullin rapidly (10-15 $\mathrm{min})$ and massively augmented the secretion of exosomes in a way dependent on AMPA- and NMDAreceptors (Lachenal et al., 2010). We also found that increasing cytosolic calcium, using the calcium ionophore ionomycin, drastically elevated exosome secretion. EM examination of cultures treated for $1 \mathrm{~min}$ with ionomycin revealed clusters of exosomes at the surface of dendrites visualizing the fusion of MVBs with the plasma membrane. Altogether, our data suggest that calcium entry through synaptic NMDA-receptors is a potent activator of MVB fusion to the plasma membrane and thereby of exosome secretion. The enhanced secretion of AMPA-R-containing exosomes following glutamatergic synaptic activation, underlines exosomal release as a way of local elimination of receptors at synapses undergoing plastic changes. The loss of AMPA receptors upon extensive synaptic activation could be a mechanism of homeostatic synaptic scaling, necessary for adjusting the strength of all of a neuron's excitatory synapses to stabilize firing (Turrigiano, 2008). Thus, while fusion of endosomes leads to an increase of receptors at synapses undergoing potentiation, sustained synaptic activation would lead to calcium increase within the dendritic shaft triggering fusion of MVBs at the base of nearby synapses to allow the local elimination of the intracellular pool of AMPA receptors and thereby synaptic down-scaling. In this scenario, regulation of the pool of surface synaptic receptors by exosome secretion would be a local event, avoiding retrograde transport of MVBs necessary to hydrolyze the receptors in lysosomes, which are only present in proximal dendrites and soma.

\section{THE FATE OF EXOSOMES RELEASED BY NEURONS}

Exosomes were first shown to be endocytosed by dendritic cells of the immune system (Skokos et al., 2003). Those released by neurons into the CNS parenchyma could potentially be endocytosed by nearby cells as shown for oligodendrocyte derived exosomes which are endocytosed by microglial cells (Fitzner et al., 2011). Astrocyte end feet, which enwrap a number of glutamatergic synapses, can also endocytose/phagocytose cellular debris (Haydon and Carmignoto, 2006) and could thus capture exosomes released at synapses. Transfer of exosomes could also occur between spines of the same neuron or across synapses to end up in afferent neurons. Indeed, the diameter of neuronal exosomes is compatible with possible endocytosis in neuronal clathrin coated pits occurring in presynaptic boutons, in spines, or dendritic shafts (Lu et al., 2007). We have recently obtained evidence that exosomes bind to and are endocytosed by hippocampal neurons (unpublished observations) and that they allow the inter-neuronal transfer of Tetanus Toxin, which is known to cross synapses in vivo (Lachenal et al., 2010). EM observations are now needed to characterize the site of entry of exosomes and their fate inside endosomes. In non-neuronal cells, the fact that exosomal RNAs can act on receiving cells demonstrates that exosome intralumenal cargoes are released into the cytosol i.e., that the membrane of exosomes fuses with the plasma membrane or with endosomal membranes after their endocytosis (Figure 1). Backfusion of intralumenal vesicles has been demonstrated to occur in MVBs (Falguieres et al., 2009) and could thus concern exosomes, which have the same origin. Such a process would lead to the entry of exosomal membrane proteins into the endosomal protein pool and possibly re-expression at the cell surface (e.g., AMPA receptors). It would also allow the release into the cytosol of the exosome content, including signal transduction molecules and miRNAs.

\section{RELEVANCE OF NEURONAL EXOSOMES FOR NEURODEGENERATIVE DISEASES}

Exosomes can contain pathogenic proteins such as alphasynuclein, PrPsc, amyloid precursor protein (APP), and phosphorylated Tau, which are involved in Parkinson's, Prion, and Alzheimer's diseases respectively. The scrapie form of the Prion protein (PrPsc) contained in exosomes is secreted via exosomes and remains infectious under this form (Fevrier et al., 2004). Thus, trans-synaptic exchange could be one way for the propagation of Prion diseases from the periphery to the CNS. Alpha-synuclein secreted together with exosomes released by neuroblastoma cells causes cell death of recipient neuronal cells suggesting that alphasynuclein secretion via exosomes serves to amplify and propagate Parkinson's disease-related pathology (Emmanouilidou et al., 2010). The catabolism of APP giving rise to the amyloidogenic C-terminal APP fragment occurs in endosomes and this fragment as well as $\mathrm{A} \beta$ amyloid peptides, are released by way of exosomes (Rajendran et al., 2006; Vingtdeux et al., 2007; Sharples et al., 2008; 
Ghidoni et al., 2011). Exosomes could therefore contribute to the spreading of the pathology throughout interconnected cortical areas. These puzzling hypotheses require in vivo work (i) to show that exosomal released from MVBs occurs in situ (ii) to find out the privileged site of this release (iii) to demonstrate transynaptic exchange of exosomes. Furthermore, even though the activity dependent-release of exosomes suggests a genuine function of exosomes in synaptic plasticity, molecular tools to specifically block MVB fusion with the plasma membrane must be developed to test this hypothesis. Nevertheless, studies on exosomes in the CNS are bound to shed new light on intercellular exchanges within the

\section{REFERENCES}

Aguzzi, A., and Rajendran, L. (2009). The transcellular spread of cytosolic amyloids, prions, and prionoids. Neuron 64, 783-790.

Arantes, R. M., and Andrews, N. W. (2006). A role for synaptotagmin VII-regulated exocytosis of lysosomes in neurite outgrowth from primary sympathetic neurons. J. Neurosci. 26, 4630-4637.

Babst, M. (2011). MVB vesicle formation: ESCRT-dependent, ESCRTindependent and everything in between. Curr. Opin. Cell Biol. 23, 452-457.

Belting, M., and Wittrup, A. (2008). Nanotubes, exosomes, and nucleic acid-binding peptides provide novel mechanisms of intercellular communication in eukaryotic cells: implications in health and disease. J. Cell Biol. 183, 1187-1191.

Brown, T. C., Correia, S. S., Petrok, C. N., and Esteban, J. A. (2007). Functional compartmentalization of endosomal trafficking for the synaptic delivery of AMPA receptors during long-term potentiation. J. Neurosci. 27, 13311-13315.

Bullmore, E., and Sporns, O. (2009). Complex brain networks: graph theoretical analysis of structural and functional systems. Nat. Rev. Neurosci. 10, 186-198.

Chatellard-Causse, C., Blot, B., Cristina, N., Torch, S., Missotten, M., and Sadoul, R. (2002). Alix (ALG-2interacting protein $\mathrm{X}$ ), a protein involved in apoptosis, binds to endophilins and induces cytoplasmic vacuolization. J. Biol. Chem. 277, 29108-29115.

Cooney, J. R., Hurlburt, J. L., Selig, D. K., Harris, K. M., and Fiala, J. C. (2002). Endosomal compartments serve multiple hippocampal dendritic spines from a widespread rather than a local store of recycling membrane. Neurosci. J. 22, 2215-2224.
Correia, S. S., Bassani, S., Brown, T. C., Lise, M. F., Backos, D. S., ElHusseini, A., Passafaro, M., and Esteban, J. A. (2008). Motor proteindependent transport of AMPA receptors into spines during longterm potentiation. Nat. Neurosci. 11, 457-466.

Ehlers, M. D. (2000). Reinsertion or degradation of AMPA receptors determined by activity-dependent endocytic sorting. Neuron 28, 511-525.

Emmanouilidou, E., Melachroinou, K., Roumeliotis, T., Garbis, S. D., Ntzouni, M., Margaritis, L. H., Stefanis, L., and Vekrellis, K. (2010). Cell-produced alpha-synuclein is secreted in a calcium-dependent manner by exosomes and impacts neuronal survival. J. Neurosci. 30, 6838-6851.

Falguieres, T., Luyet, P. P., and Gruenberg, J. (2009). Molecular assemblies and membrane domains in multivesicular endosome dynamics. Exp. Cell Res. 315, 1567-1573.

Faure, J., Lachenal, G., Court, M., Hirrlinger, J., Chatellard-Causse, C., Blot, B., Grange, J., Schoehn, G., Goldberg, Y., Boyer, V., Kirchhoff, F., Raposo, G., Garin, J., and Sadoul, R. (2006). Exosomes are released by cultured cortical neurones. Mol. Cell. Neurosci. 31, 642-648.

Fevrier, B., Vilette, D., Archer, F., Loew, D., Faigle, W., Vidal, M., Laude, H., and Raposo, G. (2004). Cells release prions in association with exosomes. Proc. Natl. Acad. Sci. U.S.A. 101, 9683-9688.

Fevrier, B., Vilette, D., Laude, H., and Raposo, G. (2005). Exosomes: a bubble ride for prions? Traffic 6, 10-17.

Fitzner, D., Schnaars, M., van Rossum, D., Krishnamoorthy, G., Dibaj, P., Bakhti, M., Regen, T., Hanisch, U. K., and Simons, M. (2011). Selective transfer of exosomes from oligodendrocytes to microglia by macropinocytosis. J. Cell. Sci. 124, $447-458$.

brain and to open new avenues toward understanding how neurodegenerative diseases spread over time throughout the nervous system.

\section{ACKNOWLEDGMENTS}

The authors are grateful to K. Sadoul and K. Laulagnier for critical reading of the manuscript and all members of the lab for helpful suggestions. Mathilde Chivet was supported by the Ministère de l'EnseignementSupérieur et de la Recherche. This work was funded by INSERM, Université Joseph Fourier, Fondation France Alzheimer, and ANR (08-Blanc-0271).

Geminard, C., De Gassart, A., Blanc, L., and Vidal, M. (2004). Degradation of AP2 during reticulocyte maturation enhances binding of hsc70 and Alix to a common site on TFR for sorting into exosomes. Traffic 5 , 181-193.

Ghidoni, R., Paterlini, A., Albertini, V., Glionna, M., Monti, E., Schiaffonati, L., Benussi, L., Levy, E., and Binetti, G. (2009). Cystatin C is released in association with exosomes: a new tool of neuronal communication which is unbalanced in Alzheimer's disease. Neurobiol. Aging 32, 1435-1442.

Ghidoni, R., Paterlini, A., Albertini, V., Glionna, M., Monti, E., Schiaffonati, L., Benussi, L., Levy, E., and Binetti, G. (2011). Cystatin C is released in association with exosomes: a new tool of neuronal communication which is unbalanced in Alzheimer's disease. Neurobiol. Aging 32, 1435-1442.

Gruenberg, J., and Stenmark, H. (2004). The biogenesis of multivesicular endosomes. Nat. Rev. Mol. Cell Biol. 5, 317-323.

Haydon, P. G., and Carmignoto, G. (2006). Astrocyte control of synaptic transmission and neurovascular coupling. Physiol. Rev. 86, 1009-1031.

Kasai, H., Matsuzaki, M., Noguchi, J., Yasumatsu, N., and Nakahara, H. (2003). Structure-stabilityfunction relationships of dendritic spines. Trends Neurosci. 26, 360-368.

Kennedy, M. J., and Ehlers, M. D. (2006). Organelles and trafficking machinery for postsynaptic plasticity. Annu. Rev. Neurosci. 29, 325-362.

Kosaka, N., Iguchi, H., Yoshioka, Y., Takeshita, F., Matsuki, Y., and Ochiya, T. (2010). Secretory mechanisms and intercellular transfer of microRNAs in living cells. J. Biol. Chem. 285, 17442-17452.

Kraev, I. V., Godukhin, O. V., Patrushev, I. V., Davies, H. A., Popov, V. I., and
Stewart, M. G. (2009). Partial kindling induces neurogenesis, activates astrocytes and alters synaptic morphology in the dentate gyrus of freely moving adult rats. Neuroscience 162, 254-267.

Lachenal, G., Pernet-Gallay, K., Chivet, M., Hemming, F. J., Belly, A., Bodon, G., Blot, B., Haase, G., Goldberg, Y., and Sadoul, R. (2010). Release of exosomes from differentiated neurons and its regulation by synaptic glutamatergic activity. Mol. Cell. Neurosci. 46, 409-412.

Laulagnier, K., Grand, D., Dujardin, A., Hamdi, S., Vincent-Schneider, H., Lankar, D., Salles, J. P., Bonnerot, C., Perret, B., and Record, M. (2004). PLD2 is enriched on exosomes and its activity is correlated to the release of exosomes. FEBS Lett. 572, 11-14.

Lu, J., Helton, T. D., Blanpied, T. A., Racz, B., Newpher, T. M., Weinberg, R. J., and Ehlers, M. D. (2007). Postsynaptic positioning of endocytic zones and AMPA receptor cycling by physical coupling of dynamin-3 to Homer. Neuron 55, 874-889.

Malenka, R. C., and Bear, M. F. (2004). LTP and LTD: an embarrassment of riches. Neuron 44, 5-21.

Maness, P. F., and Schachner, M. (2007). Neural recognition molecules of the immunoglobulin superfamily: signaling transducers of axon guidance and neuronal migration. Nat. Neurosci. 10, 19-26.

Matsuo, H., Chevallier, J., Mayran, N., Le Blanc, I., Ferguson, C., Faure, J. Blanc, N. S., Matile, S., Dubochet, J., Sadoul, R., Parton, R. G., Vilbois, F., and Gruenberg, J. (2004). Role of LBPA and Alix in multivesicular liposome formation and endosome organization. Science 303, 531-534.

Missotten, M., Nichols, A., Rieger, K., and Sadoul, R. (1999). Alix, a novel mouse protein undergoing calcium-dependent interaction with the apoptosis-linked-gene 2 (ALG2) protein. Cell Death Differ. 6, 124-129. 
Montecalvo, A., Larregina, A. T., Shufesky, W. J., Beer Stolz, D., Sullivan, M. L., Karlsson, J. M., Baty, C. J., Gibson, G. A., Erdos, G., Wang, Z., Milosevic, J., Tkacheva, O. A., Divito, S. J., Jordan, R., Lyons-Weiler, J., Watkins, S. C., and Morelli, A. E. (2012). Mechanism of transfer of functional microRNAs between mouse dendritic cells via exosomes. Blood 119, 756-766.

Morelli, A. E., Larregina, A. T., Shufesky, W. J., Sullivan, M. L., Stolz, D. B., Papworth, G. D., Zahorchak, A. F., Logar, A. J., Wang, Z., Watkins, S. C., Falo, L. D. Jr., and Thomson, A. W. (2004). Endocytosis, intracellular sorting, and processing of exosomes by dendritic cells. Blood 104, 3257-3266.

Park, M., Salgado, J. M., Ostroff, L., Helton, T. D., Robinson, C. G., Harris, K. M., and Ehlers, M. D. (2006). Plasticity-induced growth of dendritic spines by exocytic trafficking from recycling endosomes. Neuron 52, 817-830.

Pegtel, D. M., Cosmopoulos, K., Thorley-Lawson, D. A., van Eijndhoven, M. A., Hopmans, E. S., Lindenberg, J. L., de Gruijl, T. D., Wurdinger, T., and Middeldorp, J. M. (2010). Functional delivery of viral miRNAs via exosomes. Proc. Natl. Acad. Sci. U.S.A. 107, 6328-6333.

Popov, V. I., Medvedev, N. I., Kraev, I. V., Gabbott, P. L., Davies, H. A., Lynch, M., Cowley, T. R., Berezin, V., Bock, E., and Stewart, M. G. (2008). A cell adhesion molecule mimetic, FGL peptide, induces alterations in synapse and dendritic spine structure in the dentate gyrus of aged rats: a three-dimensional ultrastructural study. Eur. J. Neurosci. 27, 301-314.

Putz, U., Howitt, J., Lackovic, J., Foot, N., Kumar, S., Silke, J., and Tan, S. S. (2008). Nedd4 family-interacting protein 1 (Ndfipl) is required for the exosomal secretion of $\mathrm{Nedd} 4$ family proteins. J. Biol. Chem. 283, 32621-32627.

Rajendran, L., Honsho, M., Zahn, T. R., Keller, P., Geiger, K. D., Verkade, P., and Simons, K. (2006). Alzheimer's disease beta-amyloid peptides are released in association with exosomes. Proc. Natl. Acad. Sci. U.S.A. 103, 11172-11177.
Regehr, W. G., Carey, M. R., and Best, A. R. (2009). Activity-dependent regulation of synapses by retrograde messengers. Neuron 63, 154-170.

Rind, H. B., Butowt, R., and von Bartheld, C. S. (2005). Synaptic targeting of retrogradely transported trophic factors in motoneurons: comparison of glial cell linederived neurotrophic factor, brainderived neurotrophic factor, and cardiotrophin-1 with tetanus toxin. J. Neurosci. 25, 539-549.

Sahu, R., Kaushik, S., Clement, C. C., Cannizzo, E. S., Scharf, B., Follenzi, A., Potolicchio, I., Nieves, E., Cuervo, A. M., and Santambrogio, L. (2011). Microautophagy of cytosolic proteins by late endosomes. Dev. Cell 20, 131-139.

Savina, A., Fader, C. M., Damiani, M. T., and Colombo, M. I. (2005). Rab11 promotes docking and fusion of multivesicular bodies in a calcium-dependent manner. Traffic 6, 131-143.

Schratt, G. M., Tuebing, F., Nigh, E. A., Kane, C. G., Sabatini, M. E., Kiebler, M., and Greenberg, M. E. (2006). A brain-specific microRNA regulates dendritic spine development. Nature 439, 283-289.

Sharples, R. A., Vella, L. J., Nisbet, R. M., Naylor, R., Perez, K., Barnham, K. J., Masters, C. L., and Hill, A. F. (2008). Inhibition of \{gamma $\}$ secretase causes increased secretion of amyloid precursor protein Cterminal fragments in association with exosomes. FASEB J. 4, 4.

Siegel, G., Obernosterer, G., Fiore, R., Oehmen, M., Bicker, S., Christensen, M., Khudayberdiev, S., Leuschner, P. F., Busch, C. J., Kane, C., Hubel, K., Dekker, F., Hedberg, C., Rengarajan, B., Drepper, C., Waldmann, H., Kauppinen, S., Greenberg, M. E., Draguhn, A., Rehmsmeier, M., Martinez, J., and Schratt, G. M. (2009). A functional screen implicates microRNA138-dependent regulation of the depalmitoylation enzyme APT1 in dendritic spine morphogenesis. Nat. Cell Biol. 11, 705-716.

Simons, M., and Raposo, G. (2009). Exosomes - vesicular carriers for intercellular communication. Curr. Opin. Cell Biol. 11, 11.
Skokos, D., Botros, H. G., Demeure, C. Morin, J., Peronet, R., Birkenmeier, G., Boudaly, S., and Mecheri, S. (2003). Mast cell-derived exosomes induce phenotypic and functional maturation of dendritic cells and elicit specific immune responses in vivo. J. Immunol. 170, 3037-3045.

Steiner, P., Alberi, S., Kulangara, K. Yersin, A., Sarria, J. C., Regulier, E., Kasas, S., Dietler, G., Muller, D., Catsicas, S., and Hirling, H. (2005). Interactions between NEEP21, GRIP1 and GluR2 regulate sorting and recycling of the glutamate receptor subunit GluR2. EMBO J. 24, 2873-2884.

Stewart, M. G., Davies, H. A., Sandi, C. Kraev, I. V., Rogachevsky, V. V., Peddie, C. J., Rodriguez, J. J., Cordero, M. I., Donohue, H. S., Gabbott, P. L., and Popov, V. I. (2005). Stress suppresses and learning induces plasticity in CA3 of rat hippocampus: a threedimensional ultrastructural study of thorny excrescences and their postsynaptic densities. Neuroscience 131, 43-54.

Subra, C., Grand, D., Laulagnier, K., Stella, A., Lambeau, G., Paillasse, M., De Medina, P., Monsarrat, B., Perret, B., Silvente-Poirot, S., Poirot, M., and Record, M. (2010). Exosomes account for vesicle-mediated transcellular transport of activatable phospholipases and prostaglandins. J. Lipid Res. 51, 2105-2120.

Thery, C., Zitvogel, L., and Amigorena, S. (2002). Exosomes: composition, biogenesis and function. Nat. Rev. Immunol. 2, 569-579.

Turrigiano, G. G. (2008). The selftuning neuron: synaptic scaling of excitatory synapses. Cell 135, 422-435.

Utvik, J. K., Haglerod, C., Mylonakou, M. N., Holen, T., Kropf, M., Hirling, H., Skare, O., Laake, P., Ottersen, O. P., Haug, F. M., and Davanger, S. (2009). Neuronal enriched endosomal protein of $21 \mathrm{kDa}$ colocalizes with glutamate receptor subunit GLUR2/3 at the postsynaptic membrane. Neuroscience 158, 96-104.

Valadi, H., Ekstrom, K., Bossios, A., Sjostrand, M., Lee, J. J., and Lotvall, J. O. (2007). Exosome-mediated transfer of mRNAs and microRNAs is a novel mechanism of genetic exchange between cells. Nat. Cell Biol. 9, 654-659.

van der Goot, F. G., and Gruenberg, J. (2006). Intra-endosomal membrane traffic. Trends Cell Biol. 16, 514-521. Vingtdeux, V., Hamdane, M., Loyens, A., Gele, P., Drobeck, H., Begard, S., Galas, M. C., Delacourte, A., Beauvillain, J. C., Buee, L., and Sergeant, N. (2007). Alkalizing drugs induce accumulation of amyloid precursor protein by-products in luminal vesicles of multivesicular bodies. J. Biol. Chem. 282, 18197-18205.

Von Bartheld, C. S., and Altick, A. L. (2011). Multivesicular bodies in neurons: distribution, protein content, and trafficking functions. Prog. Neurobiol. 93, 313-340.

Wang, Z., Edwards, J. G., Riley, N., Provance, D. W. Jr., Karcher, R., Li, X. D., Davison, I. G., Ikebe, M., Mercer, J. A., Kauer, J. A., and Ehlers, M. D. (2008). Myosin Vb mobilizes recycling endosomes and AMPA receptors for postsynaptic plasticity. Cell 135, 535-548.

Conflict of Interest Statement: The authors declare that the research was conducted in the absence of any commercial or financial relationships that could be construed as a potential conflict of interest.

Received: 14 March 2012; paper pending published: 04 April 2012; accepted: 30 April 2012; published online: 28 May 2012.

Citation: Chivet M, Hemming F, PernetGallay $K$, Fraboulet $S$ and Sadoul $R$ (2012) Emerging role of neuronal exosomes in the central nervous system. Front. Physio. 3:145. doi: 10.3389/fphys.2012.00145

This article was submitted to Frontiers in Membrane Physiology and Biophysics, a specialty of Frontiers in Physiology. Copyright (c) 2012 Chivet, Hemming, Pernet-Gallay, Fraboulet and Sadoul. This is an open-access article distributed under the terms of the Creative Commons Attribution Non Commercial License, which permits non-commercial use, distribution, and reproduction in other forums, provided the original authors and source are credited. 